\title{
A HISTÓRIA DA ÁFRICA COMO RECURSO ANALÍTICO PARA UM CURRÍCULO ORIENTADO PELO MULTICULTURALISMO
}

\author{
THE HISTORY OF AFRICA AS AN ANALYTICAL RESOURCE FOR A CURRICULUM ORIENTED BY \\ MULTICULTURALISM
}

\author{
Márcio Eurélio Rios de Carvalho* \\ Kleber José dos Santos**
}

\begin{abstract}
RESUMO:
Este artigo procura demonstrar que a aplicação da recente lei que obriga o ensino de história da África no ensino fundamental (Lei 10. 639/03) deve vir acompanhada das discussões filosóficas sobre a passagem da modernidade para a pós-modernidade, a partir da filosofia da diferença, e da mudança de perspectiva do universalismo para o particularismo, como modo de romper com o discurso etnocêntrico e eurocêntrico. Envereda nas principais discussões sobre o racialismo brasileiro, apontando para a complexidade que envolve a construção das identidades culturais negras, marcadamente contingenciais, e a valorização da diferença delas correlata, o que justifica as políticas de reconhecimento como forma de dar visibilidade aos grupos raciais historicamente minorizados na sociedade brasileira.
\end{abstract}

PALAVRAS-CHAVE: História da África. Educação multicultural. Ensino de História. Política do reconhecimento. Identidade étnico-racial.

\section{ABSTRACT:}

The article proposes to demonstrate that the application of the recent law which obliges the teaching of African history in primary education (Law 10.639/03) must be accompanied by philosophical discussions about the transition from modernity to postmodernity, from the philosophy of difference, and from the change of perspective from universalism to particularism, as a way of breaking with the ethnocentric and Eurocentric discourse. It goes through the main discussions about Brazilian racialism, pointing to the complexity that involves the construction of black cultural identities, markedly contingent, and the appreciation of the correlative difference, which justifies the policies of recognition as a way of giving visibility to historically minority racial groups in the Brazilian society.

KEY WORDS: African history. Multicultural education. Teaching of history. Recognition policy. Ethnic-racial identity.

\footnotetext{
* Doutor em História pela Universidade Federal de Minas Gerais. Trabalha no departamento de História da Universidade do Estado de Minas Gerais. E-mail: eurelio2@bol.com.br.

** Doutor em Estudos Culturais pela Universidade de Aveiro (UA). Mestre em Artes Performativas pela Escola Superior de Teatro e Cinema de Lisboa (ESTC). E-mail: klaaskleberteatro@gmail.com.
} 


\section{INTRODUÇÃO}

A história da África no ensino fundamental pode ser entendida através de dois movimentos: da passagem da modernidade para a pós-modernidade e da dicotomia universal x particular como polos interdependentes. Ou seja, por um lado, na passagem da modernidade para a chamada pós-modernidade, no que isso representou em termos da mudança da noção de sujeito unitário e objetividade científica para o descentramento do sujeito e indeterminação ou ausência de sentido; por outro, na mudança total de perspectiva: do universalismo (com seu ideal de objetivismo essencialista) para o particularismo (com sua dimensão diferencial e seu subjetivismo transcendental). Dois movimentos que resumem bem a questão central de nosso objeto: o interesse pelas múltiplas identidades étnicas está intimamente atrelado à morte do sujeito. Como sabemos, com os conceitos de "universalização relativa" e "universalização diferencial" a partir do conceito de "hegemonia" de Ernesto Laclau, universal e particular não são excludentes ou antagônicos, mas interdependentes.

A obrigatoriedade da disciplina "História da África no ensino fundamental" pela Lei 10. 639/03 se justifica por fazer ascender à recente discussão sobre as ações afirmativas, o racismo e a problemática da identidade x diferença que a sustenta. Toda a preocupação com a inserção da temática no currículo, ou mais ainda, a necessidade de um currículo multiculturalmente orientado, em que a temática étnico-racial esteja em seu centro, liga-se à questão da identidade e diferença que marca a discussão filosófica, histórica, pedagógica, antropológica e, recentemente, constitui o âmago dos Estudos Culturais.

\section{DOIS MOVIMENTOS: DA MODERNIDADE PARA PÓS-MODERNIDADE E DO UNIVERSALISMO PARA O PARTICULARISMO}

Se existe algo que separa, que delimita temporalmente e diferencia a modernidade da sua sucessora, a chamada pós-modernidade, é o conteúdo do discurso colonial e pós-colonial. Como têm apontado alguns pensadores atuais da "política, poética e filosofia da diferença" (SKLIAR, 2003, p. 30), a modernidade inaugura uma "construção do tempo" (p. 43), que deseja a continuidade e a mesmidade, obstruindo um tempo descontínuo, da irrupção, ruptura e diferença. Por outro lado, ela só pode ser imaginada a partir de uma relação/determinação colonial. $\mathrm{O}$ autor sugere que o tempo da mesmidade e do outro não se coincidem: "o passado era, em síntese, a repetição da mesmidade que hoje é a irrupção da diferença” (p. 41). 
A modernidade surge como um tempo essencialmente europeu (Habermas), como metadiscurso, uma narrativa de temporalidade (Lyotard), de emergência do governo/governabilidade (Foucault), com sua ideia mais arquetípica - a ordem, em oposição ao caos. Daí a sua necessidade e esforço de definir e classificar as coisas, o outro, a partir do "é isto, é aquilo", dos atos de inclusão e exclusão (SKLIAR, 2003, p. 54). Nesse desejo de designar e denotar, "aparece o estranho, o estrangeiro, a indeterminação, o outro permanente, o sempre-sem-nome”, o inominável, conforme Derrida (SKLIAR, 2003, p. 55). O outro linear moderno "só aparece quando é nomeado", ou "vem depois, nunca antes" (SKLIAR, 2003, p. $56)$.

A pós-modernidade define-se, ao contrário e por oposição, "como um tempo paradoxal que é produto do surgimento de identidades, posições ou localizações do sujeito, que antes eram ignoradas, silenciadas, colonizadas e/ou traduzidas a um tempo e um espaço único de representação" (SKLIAR, 2003, p. 46). Ao tempo linear moderno impõe-se a ideia de "temporalidade disjuntiva". A alteridade precisa se libertar da condição de ser ou não ser para transformar-se num "estar sendo como processo e não como um estado identitário essencializado", de modo que as identidades não possam ser temporalmente alcançadas, capturadas e domesticadas. Em síntese, “o estar sendo é o acontecimento imprevisto que nos obriga a pensar mais em nosso ser, em nossa identidade, do que no ser do outro, do que em sua identidade" (SKLIAR, 2003, p. 47). Nessa perspectiva da alteridade, o outro deixa de ser visto como imutável (filosofia grega), racionalizado (filosofia moderna) ou coisificado (subjetividade moderna europeia). É um outro que sempre existiu, sempre esteve, ainda que numa temporalidade/espacialidade diversa: "suas histórias, suas narrativas, sua própria percepção de ser outro, não obedece de forma submissa à nossa ordem, à nossa sequência, à nossa determinação cronológica do tempo". Ao contrário, "problematiza nosso próprio tempo e nossa própria elaboração e organização da temporalidade" (SKLIAR, 2003, p. 62).

O segundo movimento marca a relação universalismo e particularismo, aqui representados pela história geral eurocêntrica e história da África, respectivamente. Mirta Giacaglia reflete sobre a problemática universalismo x particularismo a partir da teoria do discurso e da hegemonia proposta por Ernesto Laclau, o que permite um novo olhar sobre os processos de homogeneização do capitalismo global e das propostas do multiculturalismo a ele resistentes. De antemão, para Laclau, "as crises das perspectivas universalistas e o renovado interesse suscitado pelo tema da emergência de múltiplas identidades étnicas, nacionais, sociais e políticas, está em estreita relação com a questão da denominada 'morte do 
sujeito" (GIACAGLIA, 2014, p. 96). A explosão de novas identidades liga-se à nova problemática, no campo da filosofia política, sobre a constituição de novas subjetividades, com a derrocada do projeto humanista moderno e sua tentativa de conceber o social como totalidade objetiva e fechada (GIACAGLIA, 2014, p. 103). A questão posta por Laclau é perceber o universalismo, com seu ideal de objetivismo essencialista, e o particularismo, com sua dimensão diferencial e um subjetivismo transcendental, não como opostos antagônicos, mas por uma relação de interdependência, que se explicaria pelas noções de "universalização relativa" e "universalização diferencial", a partir do conceito de hegemonia ${ }^{1}$.

Com efeito, "ao se afirmar uma identidade particular em sua relação diferencial se está afirmando de fato uma relação de poder" (GIACAGLIA, 2014, p. 98). Mas toda identidade (particularidade) constitui-se no interior de uma totalidade - o contexto histórico (universalidade). Discutir a identidade particular é discutir o contexto social, e vice-versa. E ambos são interdependentes, pois "o sistema impede a constituição da identidade opositora ao mesmo tempo em que é condição de possibilidade de sua existência" (GIACAGLIA, 2014, p. 98/99). Daí que é possível pensar, a partir de Laclau, que "o universal não é outra coisa senão um particular que acessou uma posição dominante". De outro modo, "a universalização não é incompatível com o universalismo diferencial, mas sim, constitui seu horizonte de possibilidade" (GIACAGLIA, 2014, p. 99).

A teoria social do discurso proposta por Ernesto Laclau nos possibilita compreender as demandas curriculares a partir da leitura discursiva de disputas teóricas e políticas travadas na sociedade. Segundo ele, nas estruturas discursivas não comparecem termos positivos, mas significados que se afirmam pela distinção com os demais. Nesse sentido, o social, o político e a cultura seriam sistemas de diferenciações, caracterizados pela heterogeneidade e pela contingência. Como pontuam Diego Velasco e Vitor Barcellos,

os significados dos termos utilizados são contingenciais, dependendo das articulações feitas com outros e das disputas pela hegemonia constituidoras da sociedade. Isso equivale a afirmar que as possibilidades de significação são infinitas, pois são permeadas por relações precárias e contingentes. (VELASCO; BARCELOS, 2014, p. 264).

\footnotetext{
${ }^{1}$ A autora detalha, a partir de Laclau, as mudanças operadas no universal/particular, desde a Antiguidade, passando pelo Cristianismo e durante a Modernidade, com sua ideia de fundamento universal baseado na razão humana. Segundo ela, “o universal havia encontrado seu próprio corpo, porém este era um corpo particular: a cultura europeia entendida como expressão de uma essência humana universal (o sujeito moderno que não é outro senão o burguês alçado pelo humanismo à essência humana universal)" (GIACAGLIA, 2014, p. 97).
} 
A produção desses significados dá-se por meio da ação de duas lógicas: da equivalência (apagando as unidades diferenciais) e da diferença (estancando as cadeias de equivalência e produzindo diferenças radicais).

Para a compreensão do conceito de hegemonia, Laclau parte da formulação teórica da existência de significantes vazios. Os textos são carregados de "significantes vazios" que funcionam como elementos diferenciais "de uma vasta cadeia discursiva que articula elementos como equivalentes a si, colocando-se em uma relação de antagonismo em relação a todos os outros elementos situados fora de sua cadeia de equivalência" (LACLAU, 2011 apud VELASCO; BARCELOS, 2014, p. 265).

Nos diversos presentes históricos é possível detectar demandas que consistem em reivindicações que emergem como "lugar de mediação em uma situação estrutural de subordinação, possibilitando a construção de novos antagonismos", como entendido por Martín Retamozo (2009). Segundo o autor, as demandas se formam a partir de solicitações, reclamações e reivindicações após a identificação de situações injustas. Quando de sua formulação, elas passam "a interpelar as alteridades, afirmando sua luta pelo reconhecimento e forçando a ordem social a estabelecer mecanismos de diálogo". Nos termos de Laclau, essas demandas, que também correspondem a expectativas de diversos grupos sociais, transformam-se em luta política (LOPES, 2011 apud VELASCO; BARCELOS, 2014, p. 265).

Propomos recolocar a discussão nesses termos, a partir da teoria do discurso desses autores, que nos fazem entender as políticas afirmativas como uma disputa entre universalismo e particularismo, a partir do conceito de hegemonia (LACLAU, 2011 LACLAU; MOUFFE, 2015 - MENDONÇA, 2014). Depois das contribuições teóricas da filosofia analítica, da fenomenologia, do estruturalismo e, sobretudo, do pósestruturalismo, o campo do social estruturou-se em termos de relações de sentido. Ou seja, a ação social começou a ser observada a partir da "construção de um certo campo de sentido preexistente" que se constitui num campo discursivo dependente da "experiência das variações temporais", sendo, portanto, "profundamente histórico" (SOUTHWELL, 2014, p. 135). Embora haja diferentes abordagens de análise do discurso, "todas partilham da rejeição da noção realista de que a linguagem é um meio neutro de refletir ou descrever o mundo, e da convicção na importância central do discurso, que é uma forma de ação no mundo, na realidade social que ele constrói”" (MARQUES, 2014, p. 119).

O campo do social não deve ser entendido apenas por uma causalidade econômica, mas pelos conceitos de antagonismo social e subjetividade política: "as identidades estão 
sempre baseadas em relações antagônicas (em termos simbólicos, não físicos) com outras identidades; por essa razão, as relações sociais são sempre precárias e compreendem diversos antagonismos" (SOUTHWELL, 2014, p. 142). Assim, os sujeitos em suas práticas sociais assumem posições que não dependem de uma unidade a priori, mas são sobredeterminados por uma multiplicidade de articulações de discurso. As identidades sociais se formam a partir de inúmeros antagonismos sociais (SOUTHWELL, 2014, p. 145).

A teoria do discurso de Ernesto Laclau e Chantal Mouffe nos permite entender o currículo como "terreno particular da luta hegemônica", cujo sistema discursivo está atravessado por deslocamentos e mudanças de sentido. Ele se constitui como "uma síntese de elementos culturais (conhecimento, valores, hábitos, crenças etc) que formam uma proposta político-educacional elaborada e sustentada por diversos setores sociais, com interesses diferentes e também contraditórios". Além disso, o currículo "é uma arena de luta, em que muitos setores discutem sobre o que consideram conhecimento válido e necessário" (SOUTHWELL, 2014, p. 144).

\section{IDENTIDADES (E DIFERENÇAS) CULTURAIS NEGRAS: A PROBLEMÁTICA DA COR}

A teoria cultural contemporânea tem enfatizado que as culturas da diáspora são marcadas pela hibridização, miscigenação, mestiçagem. Como conjugar a ideia de mistura, de conjunção, de intercurso entre diferentes etnias, com a ideia de exclusividade, separação, de privilegiamento de uma etnia? Afinal, "o processo de hibridização confunde a suposta pureza e insolubilidade dos grupos que se reúnem sob as diferentes identidades nacionais, raciais ou étnicas". Mas, acompanhando a teoria do hibridismo, é possível perceber que o "terceiro espaço" (BHABHA, 2014) resultante da hibridização "não é determinado, nunca, unilateralmente, pela identidade hegemônica: ele introduz uma diferença que constitui a possibilidade de seu questionamento" (SILVA, 2014, p. 87). Alguns argumentos serão utilizados a partir da ideia de reconhecimento e sobrevivência.

Diásporas, como a dos negros africanos escravizados, por exemplo, ao colocar em contato diferentes culturas e ao favorecer processos de miscigenação, colocam em movimento processos de hibridização, sincretismo e crioulização cultural que, forçosamente, transformam, desestabilizam e deslocam as identidades originais (SILVA, 2014, p. 88). 
O debate está longe de terminar: de um lado, os que advogam a necessidade de valorização da negritude e de crítica à mestiçagem e ao racismo, apelando para conceitos de autenticidade, reconhecimento e sobrevivência (TAYLOR, 1994); de outro, os que defendem a ideia de hibridismo, de mistura, considerando que a visão anterior essencializa a identidade, quando ela deveria ser subvertida, embora reconheçam a existência do racismo. Os últimos utilizam, com frequência, metáforas que remetem à "ideia de movimento, de viagem, de deslocamento: diáspora, cruzamento de fronteiras, nomadismo". Por outro lado, "as metáforas da hibridização, da miscigenação, do sincretismo e do travestismo, também aludem a alguma espécie de mobilidade entre os diferentes territórios da identidade" (SILVA, 2014, p. 86).

Kathryn Woodward examina a importância da identidade cultural em Stuart Hall (Identidade cultural e diáspora), para quem ela deve ser entendida como "processo pelo qual se busca autenticar uma determinada identidade por meio da descoberta de um passado supostamente comum" (WOODWARD, 2014, p. 28). Hall ampara sua análise nas identidades formadas na diáspora, com base nas representações cinematográficas. Segunda ela, Hall concebe duas formas diferentes de se pensar a identidade cultural: a primeira quando "uma determinada comunidade busca recuperar a 'verdade' sobre seu passado na 'unicidade' de uma história e de uma cultura partilhadas que poderiam [...] ser representadas"; a segunda a enxerga como "uma questão tanto de 'tornar-se' quanto de 'ser"' (HALL, 1990 apud WOODWARD, 2014, p. 28), evidenciando seu caráter de reconstrução e transformação no presente. Além do mais, ele evidencia, baseando-se na différrance de Derrida, o caráter fluido do significado da identidade, que é sempre adiado, diferido, nunca completo ou fixo (WOODWARD, 2014, p. 29). Por outro lado, segundo ele, "a cultura popular negra foi „sobredeterminadae de duas formas: parcialmente por suas heranças e também por suas condições diaspóricas e isso quer dizer que o autor está entendendo que essa cultura não existe em sua forma pura, mas sim hibridizada" (ABRAMOWICZ; OLIVEIRA, RODRIGUES, 2010, p. 79).

A política de identidade (feminismo entre as mulheres, direitos civis entre os negros, política sexual de gays e lésbicas), além de ter se tornado um importante fator de mobilização política, serviu para "afirmar a identidade cultural das pessoas que pertencem a um determinado grupo oprimido ou marginalizado" (WOODWARD, 2014, p. 34). Embora em alguns espaços e temporalidades tenha havido uma concepção essencialista de separatismo ou de elaboração de uma história exclusivista, a concepção não essencialista com relação à identidade tem enfatizado que "as identidades são fluidas, que elas não são essências fixas, 
que elas não estão presas a diferenças que seriam permanentes e valeriam para todas as épocas" (WOODWARD, 2014, p. 36). Duas concepções fazem pressupor o caráter fixo da identidade, segundo estes movimentos: “a primeira está baseada na classe social, constituindo o chamado "reducionismo de classe"". Contra argumentam que outras identidades atravessam o pertencimento de classe, demonstrando que outras divisões sociais de raça, gênero e etnia são também centrais para a política de identidade; a segunda tem questionado "o essencialismo da identidade e sua fixidez como algo 'natural', isto é, como uma categoria biológica" (WOODWARD, 2014, p. 36/37), de modo a subverter as categorizações naturais e binárias $^{2}$. As duas versões do essencialismo identitário são colocadas à prova, postulando que as identidades são contingentes e não formadas por um núcleo central essencial que as distinguiria:

\begin{abstract}
A primeira fundamenta a identidade na „verdade ${ }^{e e}$ da tradição e nas raízes da história, fazendo um apelo à "realidade" de um passado possivelmente reprimido e obscurecido, no qual a identidade proclamada no presente é revelada como um produto da história. A segunda está relacionada a uma categoria „natural ${ }^{\text {ec }}$ fixa, na qual a "verdade" está enraizada na biologia. Cada uma dessas versões envolve uma crença na existência e na busca de uma identidade verdadeira. O essencialismo pode, assim, ser biológico e natural, ou histórico e cultural. De qualquer modo, o que eles têm em comum é uma concepção unificada de identidade (WOODWARD, 2014, p. $38)$.
\end{abstract}

É importante reter que a biologia e a origem trans-histórica recebem essa importância enquanto marcadoras da identidade porque fornecem "fontes de solidariedade" no interior de um grupo excluído qualquer. Mas as identidades são sobredeterminadas por contingências que emergem em momentos históricos específicos e, particularmente, nos conflitos étnicos e nos movimentos sociais em geral, elas aparecem como marcadoras de diferença, que se reproduz por meio de sistemas simbólicos (WOODWARD, 2014, p. 39-40).

Duas são as formas de marcação da diferença, segundo Woodward (2014, p. 40): por meio "dos sistemas simbólicos de representação" e por meio "de formas de exclusão social". Uma vez que as identidades são criadas a partir da diferença, pode-se concluir que elas não são opostas, mas interdependentes, ou seja, a identidade depende da diferença.

\footnotetext{
2 Tomaz Tadeu da Silva exemplifica o essencialismo cultural com as identidades nacionais, que fixam as identidades através de mitos fundadores, língua e símbolos nacionais (hinos, bandeiras e brasões), além, poderíamos completar, das datas, festas, lugares que servem de "lugares de memória" de uma nação. Se o movimento essencialista procura "fixar" as identidades, o movimento não-essencialista procura "desestabilizar", "subverter" as identidades (SILVA, 2014, p. 86).
} 
As identidades não são estáveis, são mutáveis. As identidades negras foram marcadas bruscamente por uma mudança de condição social: do status de livre para o de escravo. Acredita-se que a primeira forma de identificação tenha se dado através dos vínculos estabelecidos quando da experiência na "travessia da Calunga Grande": viam-se como parentes e tratavam-se como malungos. O destino reservado a todos (as) sobreviventes cuidaria de conformar novas identidades culturais. Mas a condição de escravidão reflete uma "síntese cultural" que "nunca foi homogênea em suas práticas e concepções, nem unitária nas faces que produziu" (SPILLERS, 1989, p. 29 apud BHABHA, 2014, p. 285).

Sendo a cultura um "código básico de simbolização que permite a comunicação e o entendimento entre aqueles que pertencem a ela" (SOUZA, 2006, p. 87), e a identidade uma "imagem que as pessoas têm de si próprias e que os outros têm delas" (p. 105), é fácil delinear como as identidades culturais negras se formaram em terras brasileiras. Alguns elementos destacam-se nessa formação: a língua falada, o lugar em que se vivia, o passado comum, os valores compartilhados, as crenças professadas, bem como a experiência da escravização e do racismo.

Como já apontado, a historiografia deu um salto qualitativo, e as identidades escravas e as identidades negras no tempo estão na ordem do dia da escrita da História. Algumas problemáticas de como elas se forjaram no passado, e ainda se formam, devem ser recuperadas no ensino de História da África e da cultura afro-brasileira. Laços de solidariedade, formas de negociação, redes de sociabilidade, variadas estratégias de resistência etc, comparecem há tempos na pesquisa e escrita da História. Atentar para essa variação é conceber que a desumanidade da escravidão na Afro-América existiu, assim como a opressão, mas que "nem todos os sistemas escravagistas oprimiram igualmente todos os escravos, e nem todos os escravos lidaram da mesma maneira com sua opressão" (MINTZ; PRICE, 2003, p. 113). Os povos africanos vindos para a América refizeram o Novo Mundo, e refizeram a si mesmos, através das mais variadas formas culturais.

A singularidade étnico-cultural brasileira faz com que todos os conceitos que tentam abarcá-la pareçam problemáticos ou, no mínimo, controversos. Mestiçagem, negritude, etnicidade, racialismo e branquidade, por um lado; cultura brasileira, pluralismo cultural, multiculturalismo, cultura afro-brasileira, africanidades brasileiras, alfabetismo da diáspora, por outro; todos, em seu conjunto, despontam na teoria sócio-históricaeducacionalantropológica brasileira, com matizes, relativismos e perspectivas por vezes perturbadoras. 
No debate envolvendo Pierre Bourdieu e Löic Wacquant com Michael Hanchard, os dois primeiros interlocutores afirmam que,

\begin{abstract}
ao sugerir maior polarização na política racial brasileira e a necessidade de afastar o movimento da política culturalista, não só [Hanchard] estava „norte-americanizando as relações sociais no Brasil, mas de alguma maneira privando o ativismo afrobrasileiro de uma de suas principais diretrizes organizadoras e um de seus principais dispositivos políticos - a cultura, enfatizando aspectos ligados a bens, serviços e recursos de articulação política, em vez de desempenho e reconhecimento cultural (HANCHARD, 2002, p. 82).
\end{abstract}

Do que Hanchard contra-argumenta, afirmando que diferenças culturais baseadas em práticas culturais distintas não são suficientes para garantir direitos civis e humanos paritários, servindo muitas vezes para endossar a marginalização/exploração ou erotização/repulsa. Concorda que "o Movimento Negro do Brasil precisou de um sentido mais comparativo do relacionamento entre política e cultura como problemática dos grupos raciais e étnicos marginalizados vivendo em sociedades multiétnicas e multiculturais" (HANCHARD, 2002, p. $83)^{3} 6$.

Na base de todo debate talvez esteja a preocupação, que perpassa toda a formação histórica brasileira, com a raça e o racismo. Embora não sejam sinônimos, e por sua inviabilidade científica, pertencem muito mais ao domínio da narrativa, do que da ciência. Por conseguinte, como representação e discurso do outro, estão associados à mesmidade/alteridade e à identidade/diferença. A discussão sobre o racialismo e/ou culturalismo afro-brasileiro passa, inevitavelmente, pela problemática desses conceitos ${ }^{4}$.

Numa visão diametralmente oposta à de Michael Hanchard e a despeito de Charles Taylor (1994) ter enfatizado a necessidade íntima que os indivíduos têm de expressar sua identidade étnico-racial, Livio Sansone prefere adotar as perspectivas teóricas de Richard Handler e Paul Gilroy, para quem outras identidades sociais podem ser mobilizadas, quando os indivíduos encontram nelas mais conforto. Ou seja, não concebem a identidade como um conceito transcultural, sugerindo, ao contrário, tratar-se de uma dinâmica, e não de uma entidade (FRIGERIO, 1999 apud SANSONE, 2007, p. 12).

\footnotetext{
${ }^{3}$ Cf. todo o debate, sobretudo os textos "Sobre as artimanhas da razão imperialista", de Pierre Bourdieu e Loïc Wacquant; "Política transnacional negra, anti-imperialismo e etnocentrismo para Pierre Bourdieu e Loïc Wacquant: exemplos de interpretação equivocada", de Michael Hanchard; e "Passos em falso da razão antiimperialista: Bourdieu, Wacquant, e o Orfeu e o Poder de Hanchard", de John French, em Estudos AfroAsiáticos, ano $24, \mathrm{n}^{\circ} 1,2002$.

${ }^{4}$ Para dados estatísticos e análises sobre as desigualdades étnico-raciais no Brasil, confira: BRASIL. LUNA; KLEIN, 2009; BRASIL, 2014.
} 
$\mathrm{Na}$ visão de Livio Sansone, outros marcadores sociais, como "índio", "nativo", "imigrante", "brasileiro" são bem mais generalizados e atribuídos a diversos grupos do que os marcadores étnico-raciais. Raça, etnicidade e racismo deles advindos são mais constantes na história de outros povos, do que na nossa história, pois "não conseguiram mobilizar o mesmo grau de emoção, e ação coletivas". Ele constata que, embora tenha havido um interesse renovado na etnia/raça nos últimos anos, a falta de compreensão e/ou interesse nas/pelas relações raciais/racialidade se dá pela "autocomplacência nacional (os brasileiros são melhores) ou à xenofilia (as coisas brasileiras são piores)" (SANSONE, 2007, p. 14).

Em função da globalização, há um paradoxo latente no uso dos símbolos étnicos: ao mesmo tempo em que eles acionam a diferença, "os modos como essa diferença se expressa são singularmente parecidos" (SANSONE, 2007, p. 14). Em contrapartida, ao mesmo tempo em que há uma produção, talvez até explosão, constante de ideologias multiculturais, através da valorização de restaurantes étnicos, world music, moda, locais de lazer, produtos explicitamente étnicos, há como contrapartida uma produção de novas formas de racismo. As chances de, através do apoio da mídia, se vender um produto cultural associado a um grupo étnico são maiores, fazendo com que cultura e etnicidade sejam vistas como equivalentes e, o que é pior, estáticas.

Por outro lado, reconhece que a carga semântica e até a popularidade da palavra "raça" dificulta seu abandono, por mais que se queira enfatizar seu aspecto não científico, ou apelar para a existência de uma única raça - a humana. Nesse sentido, os termos negritude e branquidade devem ser desconstruídos, em prol da ideia/conceito de racialização (como processos de). Isso nos permitiria, segundo ele, indicar a noção de "raça" como "uma das muitas maneiras de expressar e vivenciar a etnicidade", colocando a ênfase no fenótipo (SANSONE, 2007, p. 16). Concordemos ou não com essa visão, o autor tem razão ao constatar dois curiosos fenômenos: a perda da singularidade cultural tem levado à valorização da etnicidade, e a política de identidades específicas tem sobressaído num momento de valorização do multiculturalismo.

O autor parece ratificar o pensamento de Pierre Bourdieu (Sobre as artimanhas da razão imperialista), para quem a imagem da raça/etnia americana tem se infiltrado nas relações sociais dos países latino-americanos, que nunca tiveram distinções étnicas e movimento da negritude de forma explícita, em função dos diferentes modos de racismo vivenciado em cada sociedade (one-drop-rule ou racismo de sangue/origem entre os norteamericanos, e racismo de marca/cor entre nós). Tentar forçar uma coesão étnica baseada 
somente na cor pode desaguar numa interpretação monolítica das relações raciais que não se adequa a um país de "negritude sem etnicidade", título dado a seu livro.

Nossas fronteiras étnicas pouco claras, nossas identidades ambíguas, nossa mestiçagem ou nosso padrão ambíguo de relações raciais nos afastam do modelo polarizado, claro e dicotômico dos países anglo-saxônicos. Devemos concordar com o autor quando afirma que nossa negritude,

não é uma categoria racial fixada numa diferença biológica, mas uma identidade racial e étnica que pode basear-se numa multiplicidade de fatores: o modo de administrar a aparência física negra, o uso de traços culturais associados à tradição afro-brasileira (particularmente na religião, na música e na culinária), o status, ou uma combinação desses fatores. (SANSONE, 2007, p. 25).

Nossa negritude, talvez por influência de Melville Herskovits, Roger Bastide e Pierre Verger, baseia-se no passado (uma origem localizada na África) e na tradição (referência a proximidade da natureza, a poderes mágicos, à linguagem corporal, à sexualidade, ao sensualismo). Do contrário, nos EUA, a partir de W. B. Du Bois, a identidade negra e a questão racial sempre estiveram atreladas a um problema político (SANSONE, 2007, p. 26).

Paradoxalmente, a globalização econômica e a ideia de espaço/aldeia global dela derivada tem acentuado a guetização de culturas, e o retorno de etnias e culturas locais. Stuart Hall afirma que as crises presentes na sociedade contemporânea tem sido por ou assumido um caráter multicultural ou etnizado. No mundo pós-colonial, os processos da globalização e os processos migratórios fazem crer que as identidades mantêm uma correspondência com os passados históricos que se projetam de forma mutante no presente, em busca de um porvir:

\footnotetext{
Elas têm a ver, entretanto, com a questão da utilização dos recursos da história, da linguagem e da cultura para a produção não daquilo que nós somos, mas daquilo no qual nos tornamos. Têm a ver não tanto com as questões "quem nós somos" ou "de onde viemos", mas muito mais com as questões "quem nós podemos nos tornar", "como nós temos sido representados" e "como essa representação afeta a forma como nós podemos representar a nós próprios". Elas têm tanto a ver com invenção da tradição quanto com a própria tradição. (HALL, 2014, p. 109).
}

Por meio de narrativizações do eu, as identidades estão compostas por um elemento imaginário e simbólico, e só podem ser compreendidas "no interior de formações e práticas discursivas específicas", emergindo em relações pontuais de poder e constituindo-se como "produto da marcação da diferença e da exclusão, do que o signo de uma unidade idêntica, naturalmente constituída" (HALL, 2014, p. 109). Assim como Foucault reconceitualizou o 
sujeito, a partir de uma "teoria da prática discursiva" na qual ele está inevitavelmente envolvido, mas que o ultrapassa; assim como Stephen Heath reconceitualizou a ideologia como a interseção entre ou junção do sujeito às estruturas de significação, Stuart Hall concebe 13 a identidade como um "ponto de sutura" entre as práticas discursivas de significação que nos interpelam para que assumamos determinados papéis/lugares, e os processos envolvidos na construção interna das subjetividades (HALL, 2014, p. 111-112). As identidades

são as posições que o sujeito é obrigado a assumir [...], são representações, que a representação é sempre construída ao longo de uma "falta", ao longo de uma divisão, a partir do lugar do Outro e que, assim, elas não podem nunca ser ajustadas - idênticas - aos processos de sujeito que são nelas investidos (HALL, 2014, p. 112).

Existe uma articulação, na medida em que além da convocação (chamamento/interpelação) é preciso haver o investimento por parte do sujeito para o fechamento ou a "suturação" do processo identitário. Como o próprio Stuart Hall reconhece, esse quadro já fora esboçado, e criticado, por Althusser (Os aparelhos ideológicos de Estado, 1971) em sua análise da ideologia como reprodutora das relações sociais de produção (função materialista) e constituidora do sujeito (função simbólica), empréstimo feito à teoria lacaniana. E ela é tanto mais eficaz quanto maior é sua ação sobre os níveis rudimentares da identidade e do psiquismo (ROSE, 1986 apud HALL, 2014, p. 113), e das "práticas discursivas que constituem o campo social" (HALL, 2014, p. 114). A identidade surge no ponto de interseção entre o psiquismo e o social ${ }^{5}$.

Em nossa formação histórica, a base multicultural está fortemente presente e, em toda ela, as relações interétnicas têm sido uma constante permeada pela violência e exclusão dos grupos indígenas, africanos e afrodescendentes. As consequências advindas da escravidão enraizaram-se nas práticas culturais, no plano das representações e no imaginário social, baseadas na negação do outro, na rejeição do diferente e na tentativa de anulação de sua subjetividade. Portanto, o ensino da História e cultura indígena e dos afrodescendentes, bem como da nossa ascendência africana, estão atrelados a um passado que se recusa a passar. E, mais ainda, a discussão muito atual sobre a necessidade de reparações e de ações afirmativas, de um modo geral, relaciona-se a um dever da memória do sofrimento experienciado por

\footnotetext{
${ }^{5}$ Para uma análise minuciosa sobre a formação da subjetividade baseada nos processos psíquicos de formação do inconsciente e da relação com o outro, confira os argumentos presentes em HALL, 2014.
} 
esses grupos e em função do racismo que teima em persistir (ABREU; MATTOS; DANTAS, 2009).

Não se pode menosprezar o fato de que o estigma da cor sempre serviu para hierarquizar livres e escravos, como também livres que descendiam de antigos escravizados. A fenotipia "negra" serviu para a perpetuação de formas discriminatórias para além da escravidão. As ambiguidades da identidade negra no Brasil, indissociadas da experiência da escravidão moderna, lançam possibilidades para se romper com a perspectiva essencialista das relações entre identidade e cultura. No texto "Ensino de História e luta contra a discriminação racial no Brasil”, Hebe Mattos (2003) nos ensina que tal identidade não foi criada como contrapartida direta de práticas culturais africanas, mas como resposta à difusão do racismo nas sociedades americanas (ABREU; SOIHET, 2009, p. 129). Identidade e essência culturais associadas superficialmente fazem perder de vista os intercâmbios culturais, os processos de hibridez e o sincretismo de ideias. Ao neutralizar a diferença, essa associação ligeira não permite vê-las sob o prisma histórico-cultural, reduzindo-as ao biológico-genético.

Como tudo nas Ciências Sociais e, mais especificamente na História, não houve um consenso entre os profissionais com relação à dinâmica e proporção tomada pelo novo formato curricular. De um lado, há os que se mostram defensores da implantação de um currículo específico sobre a problemática, embora apontem os silêncios e omissões das Leis 10. 639/03 e 11. 645/08 e das diretrizes correlatas; de outro, os que se mostram reticentes a elas em função da polaridade étnico-identitária que promovem, advogando que trazem em seu bojo o apagamento da possibilidade identitária da mestiçagem. De um lado, Munanga (2005/2006), Martha Abreu; Hebe Mattos (2008), Mônica Lima (2009), Marina de Mello e Souza (2009) escreveram importantes textos justificando a necessidade de valorização do currículo diferenciado, voltado para a defesa da inserção de uma história da África no ensino. De outro, aparecem visões historiográficas mais críticas com relação à explicitação dos conflitos raciais e à bipolarização histórica entre negros e brancos, tal como prescritas nos documentos oficiais, sobretudo nas Diretrizes. Júnia Sales Pereira (2008, 2014), José Roberto Pinto de Góes (2004, 2006, 2007) e Livio Sansone (2007) parecem se enquadrar nessa vertente. Para estes, embora o discurso da mestiçagem tenha servido para enfatizar um país sem preconceito e tenha sido ineficaz no combate ao racismo, a explicitação da negritude a partir da separação de brancos e todos os outros não brancos (negros) faria com que a mestiçagem fosse posta como "ideia fora do lugar". A bipolaridade não corresponde a arena multicultural presente nas relações étnico-raciais marcadas pela pluralidade. Outros parecem 
oscilar entre estes dois polos, tentando encontrar um denominador comum, o da especificidade de um racismo numa sociedade marcada pelo pluralismo étnico (D ${ }^{e}$ ADESKY, 2002, 2009).

\section{POLÍTICAS DO RECONHECIMENTO}

É possível pensar as ações afirmativas, a demarcação e proteção de territórios remanescentes de quilombos de 2003, a inserção da história da África no currículo escolar também de 2003, o estatuto da igualdade racial de 2010, o sistema de cotas vindo de 2003 e cuja decisão de constitucionalidade pelo STF foi apenas em 2012, como formas de discriminação positiva de/para um grupo subordinado e excluído historicamente da/na sociedade brasileira, a partir das relações de poder que se definem na relação entre grupos sociais. O debate sobre ações afirmativas e multiculturalismo se inscreve nessa problemática. A questão da discriminação positiva (ou política afirmativa), cujo maior exemplo é o sistema de cotas, reflete não só a problemática da igualdade e universalidade, mas na discussão de "como reconciliar a igualdade e a universalidade pela via da diferença". Segundo Marcelo de Souza Magalhães, foi com o multiculturalismo que a sociedade passou "a ser entendida como uma rede instável de posições individuais, de grupos sociais heterogêneos”, e coube ao Estado "gerenciar a manutenção das diferenças entre os grupos sociais" (MAGALHÃES, 2009, p. 179). Baseando-se em Guy Hermet (1996), o autor pondera que a dificuldade de se pensar a cidadania nesses termos do pluralismo democrático é que o "compromisso prioritário seria com o grupo primordial, e não mais com a comunidade cívica" (HERMET, 1996, p. 327 apud MAGALHÃES, 2009, p. 179) ${ }^{6}$.

Especificamente quanto às políticas de reconhecimento das identidades raciais, a relutância se dá a partir de dois argumentos: se haveria uma possível ameaça à identidade comum nacional, e se reforçaria a exaltação da consciência racial. Peter Fry, por exemplo, argumenta que com a ação afirmativa desfez-se a "mistura racial" para se produzir uma bipolaridade racial nunca existente na cultura brasileira: "O Brasil é agora imaginado como

\footnotetext{
${ }^{6}$ Para a constatação da existência de um modo de vida multicultural no Ocidente desde o fim do século XX, apontando que embora o termo multiculturalismo esteja associado à raça, tem sido adotado para outros tipos de diversidade, confira KINCHELOE; STEINBERG, 1999. Para uma análise sobre os diversos tipos de multiculturalismo, confira McLAREN, 1997. Para uma crítica ao multiculturalismo como um discurso travestido de hibridismo, mas de acentuada conotação capitalista, confira ZIZËK, 1998.
} 
uma sociedade de „raçase e ,etnias ${ }^{e e}$ distintas. As políticas de ação afirmativa racial terão a consequência de estimular os pertencimentos „raciais “, assim fortalecendo a crença em raças” (FRY, 2005, p. 336).

De fato, constata Munanga, o Movimento Negro Brasileiro vem se inspirando no Black norte-americano, na tentativa de conscientizar negros e mestiços em torno de uma mesma identidade inspirada no conceito de "negro", como forma de minimizar a discriminação racial camuflada na ideologia da mistura racial (mestiçagem) e da sua contrapartida democracia racial. Mas não se pode inferir que tal definição bipolar tenha nascido há uma década, com as políticas de ação afirmativa, estando presente há trinta anos no seio da ideologia negra presente naquele movimento.

Além de ser impossível que tal ideologia desfaça a "mistura racial", traço fundante da história étnico-racial brasileira, o conteúdo da raça vem para primeiro plano, por sua adequação sócio-política, e não biológica. $\mathrm{O}$ argumento central do artigo de Munanga é que o problema fundamental não é a raça, e sim o racismo dela decorrente. Na verdade, o conceito de raça tem sido substituído hoje pelos conceitos de "diferenças culturais e identitárias", o que não minimiza o racismo que encobre e parasita outros conceitos (MUNANGA, 2005/06, p. 53).

A discussão proposta por K. Anthony Appiah no texto Identidade, autenticidade, sobrevivência: sociedades multiculturais e reprodução social tem o mérito de alinhavar as duas dimensões de toda identidade: a coletiva e a pessoal. A identidade cultural (coletiva) está associada à identidade individual, mas apenas as primeiras contam como categorias sociais, a saber: a religião, o sexo, a etnicidade, a raça e a sexualidade. Elas dependem, de alguma maneira, de certas propriedades, como a ascendência e o corpo sexual, que são concebidas como não opcionais e/ou tendem a ser centrais para a infância, relações intergeracionais e vida familiar. Constituem-se como "identidades manuscritas", ao contrário das identidades pessoais ou profissionais, no sentido de que fornecem um problema (APPIAH, 1994, p. 167 e 176).

A sexualidade, o gênero, a religião e a etnia/raça são conteúdos culturais e centrais na experiência de vida das pessoas porque a identidade se forma dialogicamente e, muitas vezes, de forma negativa. Daí a necessidade, por oposição, de expressá-las através da ética da autenticidade, única capaz de resgatar "o que centralmente somos" por meio da exigência de reconhecimento, enquanto homossexuais, mulheres, católicos, negros etc. (APPIAH, 1994, p. 177). Se a cultura ratifica "manuscritos negativos" dessas identidades, cabe às pessoas que 
sofrem um não reconhecimento ou um reconhecimento deformado transformá-las em "manuscritos positivos", de modo que, por exemplo,

\begin{abstract}
ser negro é recodificado por ser Preto, e isto exige, entre outras coisas, a recusa em assimilar normas de discurso e de comportamento brancas. [...] Neste contexto, insistir no direito de viver uma vida digna não será suficiente. Nem sequer será suficiente exigir ser tratado com igual dignidade apesar de se ser Preto, pois isso irá exigir uma concessão de que ser Preto conta naturalmente ou até certo ponto contra a nossa dignidade. E então acabaremos por pedir para sermos respeitados enquanto negros. (APPIAH, 1994, p. 177).
\end{abstract}

Se o indivíduo molda o seu "eu" de forma autêntica enquanto afro-americano, ele procurará seu reconhecimento enquanto tal. Não basta que ele tenha um modo dele próprio, ou que precise lutar contra convenções sociais criadas pelos brancos, pois a sua identidade é moldada através do diálogo e entendimento com outras pessoas, por "conceitos e práticas disponíveis [...] através da religião, da sociedade, da escola e do estado, e mediado a vários graus pela família” (APPIAH, 1994, p. 170). E tal identidade não é criada somente, como se acredita, no interior de comunidades afro-americanas, mas inserida no conjunto total da sociedade de brancos e não brancos. A saída não é encontrar um "eu" autêntico a espera de ser decifrado ou desenterrado, e muito menos uma invenção a ser escolhida, pois "inventamos eus a partir de um estojo de opções a nossa disposição através da cultura e da sociedade. Fazemos realmente opções, mas não determinamos as opções entre as que escolhemos" (APPIAH, 1994, p. 171).

O ponto forte de sua análise refere-se ao desejo inato de sobrevivência. Ao contrário de Charles Taylor, para quem tal desejo "exige a existência continuada da cultura através de gerações futuras indefinidas", Appiah recoloca a questão em outros termos. O liberalismo processual deve ser repensado de modo que os objetivos coletivos (as práticas culturais) legítimos sejam satisfeitos pelos viventes e descendentes da atual geração. Os "princípios éticos da dignidade igual" devem ser projetados do indivíduo a toda a coletividade. Ou seja, é preciso criar no presente "uma cultura que os nossos descendentes irão querer continuar, [de modo que] a nossa cultura irá sobreviver neles" (APPIAH, 1994, p. 174). E pra isso a mudança se opera entre os nossos contemporâneos através da educação:

[...] temos de apelar e transmitir valores mais substancialmente do que um respeito pelos procedimentos liberais. O processualismo liberal tende a permitir ao estado ser indiferente entre uma variedade de concepções do bem, mas a própria variedade irá depender do que acontece na educação. Ensinar as crianças apenas que devem aceitar uma política na qual as concepções do bem de outras pessoas não sejam 
dominadas e riscamos uma situação na qual existem concepções substantivas do bem incompatíveis com o princípio liberal [...]. (APPIAH, 1994, p. 174).

Não é acidentalmente que a educação esteja no domínio político e esteja comandada por governos: "a reprodução social inclui objetivos colectivos". Assim como as identidades de sexo e nacionais, as identidades étnicas "se encaixam em cada história individual para uma grande narrativa" da identidade coletiva que compete a cada um de nós formarmos (APPIAH, 1994, p. 175).

Francine Saillant ocupa-se da problemática do reconhecimento e reparações exigidas pelo Movimento Negro no Brasil, estabelecendo os vínculos entre identidade, experiência da minorização e injustiça histórica. Amparando-se em Axel Honneth, afirma ser o reconhecimento baseado em três níveis: o nível ou plano intersubjetivo (individual/intrafamiliar) que se liga ao reconhecimento afetivo; o nível intracomunitário (escola/trabalho) - o reconhecimento dos pares; e o nível jurídico (direito/plano normativo), o reconhecimento do Estado pelo direito. De Charles Taylor e Nancy Fraser, a autora recupera a noção de identidade, atrelada ao reconhecimento:

\footnotetext{
é através do reconhecimento do outro que também reconhece você como outro que a identidade positiva se tornaria possível. A ausência de reconhecimento, a rejeição do indivíduo ou da coletividade na inexistência social e as patologias do social conduzem a uma identidade negativa e problemática. (SAILLANT, 2016, p. 19).
}

Em função disso, Taylor tinha razão ao insistir na "questão da identidade negativa, da baixa autoestima e do sofrimento como uma consequência da falta de reconhecimento" (SAILLANT, 2016, p. 19). Além disso, o sofrimento social ocasionado pela ausência de reconhecimento não é apenas uma questão individual, mas algo que resulta de interações coletivas, que levam ao racismo, segregacionismo, sexismo etc.

Por outro lado, a experiência da minorização pela falta de reconhecimento ultrapassa a propriedade de ser minoria, pois "introduz a dimensão do valor que seria, em princípio, a parte qualitativa da experiência de ser minoria. O fato de ser minorizado (pela maioria) significa ser diminuído ou enfraquecido aos olhos da maioria" (SAILLANT, 2016, p. 21). Por se basear num constructo identitário da falta ou déficit, a experiência da minorização liga-se a ausência de reconhecimento.

E se a injustiça histórica persiste durante gerações sem nenhuma reparação de um mal cometido, a experiência da minorização está “ancorada numa profundeza histórica e vindo 
assombrar a memória e a identidade do grupo minorizado" (SAILLANT, 2016, p. 23). Isso é o que ocorreu com os indígenas no processo de colonização e com os africanos e afrodescendentes com a escravidão:

\footnotetext{
o reconhecimento da injustiça histórica é essencial para o reconhecimento da coletividade tocada por este mal, particularmente porque os membros da coletividade minorizada são afetados na sua condição social (o problema das desigualdades) e na sua identidade (o problema das atribuições negativas). (SAILLANT, 2016, p. 24).
}

Esse mal deve ser associado a uma violação dos direitos humanos e por isso sua reparação está ligada à justiça transicional, podendo passar-se por "compensações financeiras, restituição de bens, reabilitação das vítimas, procura e restabelecimento da verdade histórica e garantia de não repetição do mal" (SAILLANT, 2016, p. 26). Segundo a autora, não se deve reduzir a questão da reparação ao âmbito do Direito e do Estado, como as ações simbólicas (desculpas públicas ou apology), afinal o reconhecimento de um grupo minorizado, pode enfatizar a dimensão cultural das reparações e não a sua dimensão jurídico-política. Este é o caso de setores em que a reparação se evidencia no interior da sociedade civil, como a valorização das religiões de matriz africana, que se impôs como autoridade religiosa a partir "de baixo" desde o século XIX; a valorização da cultura identitária negra, através da veiculação positiva de imagens (fotografias e vídeo) por meio da ação coletiva; e a formação de um patrimônio afro-brasileiro que recupera não só a história da escravidão, mas também desenvolve políticas culturais de reconhecimento de uma cultura afro-brasileira que se constituiu às margens da instituição da escravidão (como exemplo, a Rota dos Escravos e o museu do Valongo).

Portanto, ao conjugar o reconhecimento jurídico-político e o reconhecimento cultural, conforme acepção de Axel Honneth, pode-se afirmar que "as reparações são em si ações de reconhecimento" (SAILLANT, 2016, p. 45). A ideia de reparação veiculada pelo Movimento Negro no Brasil optou por uma fórmula semelhante ao modelo americano, que afasta a noção de reparação como compensação financeira, e se aproxima da "articulação de pedidos de reparação na forma de ações afirmativas" (SAILLANT, 2016, p. 38). Se desde 1988, a regularização da propriedade quilombola pode ser considerada a primeira forma reparadora dos males do passado, foi nos anos 2000 que acontecem uma guinada na articulação dos pedidos de reparação, com a criação, em 2003, da Secretaria para a Promoção das Políticas de Igualdade Racial (SEPPIR), da lei que obriga o ensino da História da África e da Cultura 
afrobrasileira nas escolas públicas (Lei 10. 639), e do Decreto 4.887 que operacionalizou o reconhecimento dos quilombos em território brasileiro. A aprovação do Estatuto da Igualdade Racial de 2010 abriu "caminho à nova legislação no campo da igualdade racial em vários setores da vida social, da mídia, da saúde e da educação" (CICALO, 2016, p. 61), e a Lei 12.711 de 2012 permitiu uma reserva (cotas raciais) de 50\% das vagas em universidades e institutos federais para afrodescendentes. Finalmente, as Diretrizes Curriculares Nacionais para a Educação Escolar Quilombola, aprovada em 20 de novembro de 2012, aproximou a "prática educacional em territórios quilombolas da realidade sociocultural e política desses grupos" (YABETA, 2016, p. 104).

De um modo geral, “as ações estruturantes no campo da educação (grande público, meios políticos, jovens) foram vistas como fornecedoras das melhores armas aos jovens para sair da pobreza, da quase-cidadania (e do não reconhecimento)" (SAILLANT, 2016, p. 40). Mas não bastam ações oficiais para dar início ao processo de reconhecimento de grupos minorizados como os afro-brasileiros; é preciso que a sociedade e o Estado conjuntamente rompam com o silêncio e criem ações em nível cultural e político para reparar os danos causados pela escravidão, pelo pós-Abolição e por todas as ideologias do branqueamento, mestiçagem e de democracia racial que procuraram invizibilizar esses grupos.

\section{CONCLUSÃO}

A inserção da disciplina História da África e da cultura afro-brasileira no ensino fundamental deve vir acompanhada da discussão conceitual sobre a passagem da modernidade para a pós-modernidade, que insere a problemática da constituição de novos sujeitos e novas identidades à luz da "política, poética e filosofia da diferença". Deve igualmente adotar a perspectiva da filosofia política que instaura um novo olhar sobre a passagem do universalismo para o particularismo, representado pelas identidades étnicas, sociais e de gênero que têm substituído a atenção dada à identidade nacional. As identidades étnico-raciais negras formaram-se no passado, mas são reelaboradas constantemente a partir da diferença delas correlata. As identidades são fluidas e não devem ser vistas como essências imutáveis e permanentes, afinal foram forjadas por suas heranças e por suas condições diaspóricas. Por outro lado, é preciso reconhecer que as políticas da diferença esbarram na controvérsia sobre o conteúdo culturalista e/ou político delas inerente, objeto de debates quanto às especificidades da política racial brasileira. Ainda que nossa negritude tenha se forjado sem 
etnicidade, as políticas de reconhecimento, aliadas ao desejo de autenticidade e sobrevivência, servem para legitimar a necessidade de reparação a todos os afro-descendentes que sofrem de discriminação pelo estigma da cor que ainda persiste em nossas relações sociais.

\section{REFERÊNCIAS}

ABRAMOWICZ, Anete; OLIVEIRA, Fabiana de; RODRIGUES, Tatiane Cosentino. A criança negra, uma criança e negra. In: ABRAMOWICZ, Anete; GOMES, Nilma Lino (orgs.). Educação e raça: perspectivas políticas, pedagógicas e estéticas. BH: Autêntica, 2010.

ABREU, Martha; SOIHET, Rachel (Org.). Ensino de história: conceitos, temáticas e metodologia. $2^{\mathrm{a}}$ ed. RJ: Casa da Palavra, 2009.

ABREU, Martha; MATTOS, Hebe. Em torno das "Diretrizes curriculares nacionais para a educação das relações étnico-raciais e para o ensino de história e cultura afro-brasileira e africana": uma conversa com historiadores. Estudos Históricos, Rio de Janeiro, v. 21, n 41, p. 5-20, jan-jun 2008.

ABREU, Martha; MATTOS, Hebe; DANTAS, Carolina Vianna. Em torno do passado escravista: as ações afirmativas e os historiadores. In: ROCHA, Helenice Aparecida Bastos; MAGALHÃES, Marcelo de Souza; GONTIJO, Rebeca (Org.). A escrita da história escolar: memória e historiografia. RJ: FGV, 2009.

APPIAH, K. Antony. Identidade, Autenticidade, Sobrevivência: sociedades multiculturais e reprodução social. In: TAYLOR, Charles (Org). Multiculturalismo: examinando a política de reconhecimento. Lisboa: Instituto Piaget,1994.

BHABHA, Homi K. O local da cultura. 2a Ed. Belo Horizonte: Ed. UFMG, 2014.

BRASIL. Relatório de Desenvolvimento Humano - Brasil 2005: racismo, pobreza e violência. Brasília: PNUD (Programa das Nações Unidas para o Desenvolvimento), 2005.

BRASIL. Situação social da população negra por estado. Instituto de Pesquisa Econômica Aplicada / Secretaria de Políticas de Promoção da Igualdade Racial. Brasília: IPEA, 2014.

CICALO, André. Uma voz para o passado: a construção de patrimônio da escravidão na região portuárias do Rio de Janeiro. In: MATTOS, Hebe (Org.). História oral e comunidade: reparações e culturas negras. São Paulo: Letra e Voz, 2016.

COSTA, Warley da. A escrita escolar da história da África e dos afro-brasileiros: entre leis e resoluções. In: PEREIRA, Amilcar Araújo; MONTEIRO, Ana Maria. Ensino de história e culturas afro-brasileiras e indígenas. Rio de Janeiro: Pallas, 2013.

D’ADESKY, Jacques. Multiculturalismo e educação. CADERNOS PENESB/UFF Programa de Educação Sobre o Negro na Sociedade Brasileira. Relações raciais e educação: temas contemporâneos. Rio de Janeiro/Niterói, n. 4, 2002. 
D’ADESKY, Jacques. Pluralismo étnico e multiculturalismo: racismos e anti-racismos no Brasil. Rio de Janeiro: Pallas, 2009.

FRY, Peter. A persistência da raça: ensaios antropológicos sobre o Brasil e a África Austral. Rio de Janeiro: Civilização Brasileira, 2005.

GIACAGLIA, Mirta. Universalismo e particularismo: emancipação e democracia na teoria do discurso. In: MENDONÇA, Daniel de; RODRIGUES, Léo Peixoto. Pós-estruturalismo e teoria do discurso: em torno de Ernesto Laclau. 2a ed. Porto Alegre: EDIPUCRS, 2014.

GILROY, Paul. O atlântico negro: modernidade e dupla consciência. Tradução Cid Knipel Moreira. $2^{\mathrm{a}}$ ed. São Paulo: Editora 34; RJ: UCAM/Centro de Estudos afro-Asiáticos, 2012.

GÓES, José Roberto Pinto de. O racismo vira lei. O Globo, Rio de Janeiro, 16 ago. 2004.

GÓES, José Roberto Pinto de. Os manifestos e a escrava Inês. O Globo, Rio de Janeiro, 14 de jul. 2006.

GÓES, José Roberto Pinto de. Negros: uma história reparada. Inteligência, Rio de Janeiro, set. 2007.

HALL, Stuart. Quem precisa da identidade. In: SILVA, Tomaz Tadeu da; HALL, Stuart; WOODWARD, Kathryn (Org.). Identidade e diferença: a perspectiva dos estudos culturais. $15^{\mathrm{a}}$ ed. Petrópolis, RJ: Vozes, 2014.

HANCHARD, Michael. Política transnacional negra, antiimperialismo e etnocentrismo para Pierre Bourdieu e Löic Wacquant: exemplos de interpretação equivocada. Estudos AfroAsiáticos, ano 24, $\mathrm{n}^{\mathrm{o}}$ 1, 2002.

HARTOG, François. Evidência da história: o que os historiadores vêem. Belo Horizonte: Autêntica, 2013.

KINCHELOE, Joe; STEINBERG, Shirley. Repensar el multiculturalismo. Barcelona: Octaedro, 1999.

LACLAU, Ernesto. Emancipação e diferença. Rio de Janeiro: EdUERJ, 2011.

LACLAU, Ernesto; MOUFFE, Chantal. Hegemonia e estratégia socialista: por uma política democrática radical. São Paulo: Intermeios, Brasília: CNPq, 2015.

LIMA, Mônica. Aprendendo e ensinando história da África no Brasil: desafios e possibilidades. In: ROCHA, Helenice Aparecida Bastos; MAGALHÃES, Marcelo de Souza; GONTIJO, Rebeca (Org.). A escrita da história escolar: memória e historiografia. Rio de Janeiro: FGV, 2009.

LUNA, Francisco Vidal; KLEIN, Herbert S. Desigualdades e indicadores sociais no Brasil. In: SCHWARTZMANN, Luisa Farah et al (Org.). O Sociólogo e as políticas públicas: ensaios em homenagem a Simon Schwartzmann. Rio de Janeiro: FGV, 2009. 
McLAREN, Peter. Multiculturalismo crítico. São Paulo: Cortez, 1997.

MAGALHÃES, Marcelo de Souza. História e Cidadania: por que ensinar história hoje? In: ABREU, Martha; SOIHET, Rachel. Ensino de história: conceitos, temáticas e metodologia. $2^{\mathrm{a}}$ ed. Rio de Janeiro: Casa da palavra, 2009.

MARQUES, Luciana Rosa. Contribuição da democracia radical e da teoria do discurso de Ernesto Laclau ao estudo da gestão da educação. In: MENDONÇA, Daniel de; RODRIGUES, Léo Peixoto. Pós-estruturalismo e teoria do discurso: em torno de Ernesto Laclau. $2^{\mathrm{a}}$ ed. Porto Alegre: EDIPUCRS, 2014.

MATTOS, Hebe (Org.). História oral e comunidade: reparações e culturas negras. SP: Letra e Voz, 2016.

MENDONÇA, Daniel de; RODRIGUES, Léo Peixoto. Pós-estruturalismo e teoria do discurso: em torno de Ernesto Laclau. 2a ed. Porto Alegre: EDIPUCRS, 2014.

MINTZ, Sidney W.; PRICE, Richard. O nascimento da cultura afro-americana: uma perspectiva antropológica. RJ: Pallas/Universidade Cândido Mendes, 2003.

MONTEIRO, Ana Maria et al. Pesquisa em ensino de história: entre desafios epistemológicos e apostas políticas. Rio de Janeiro: Mauá x Faperj, 2014.

MONTEIRO, Ana Maria. Professores de história: entre saberes e práticas. Rio de Janeiro: Mauad X, 2007.

MUNANGA, Kabengele. Origem e histórico do quilombo na África. Revista USP, São Paulo, n. 28, dez/fev 1995/1996.

MUNANGA, Kabengele. Algumas considerações sobre "raça", ação afirmativa e identidade negra no Brasil: fundamentos antropológicos. Revista USP, São Paulo, n. 68, p. 46-57, dez/fev 2005/06.

PEREIRA, Júnia Sales. Reconhecendo ou construindo uma polaridade étnico-identitária? Desafios do ensino de história no imediato contexto pós-Lei $n^{0} 10.639$. Estudos Históricos, Rio de Janeiro, v. 21, nº 41, p. 21-43, jan-jun 2008.

ROCHA, Helenice Aparecida Bastos; MAGALHÃES, Marcelo de Souza; GONTIJO, Rebeca (orgs). A escrita da história escolar: memória e historiografia. RJ: FGV, 2009.

SAILLANT, Francine. Reconhecimento e reparações: o exemplo do movimento negro no Brasil. In: MATTOS, Hebe (Org.). História oral e comunidade: reparações e culturas negras. SP: Letra e Voz, 2016.

SANSONE, Livio. Negritude sem etnicidade: o local e o global nas relações raciais e na produção cultural negra do Brasil. Tradução Vera Ribeiro. Salvador: EDUFBA/Pallas, 2007. 
SILVA, Tomaz Tadeu. A produção social da identidade e da diferença. In: SILVA, Tomaz Tadeu (org.). Identidade e diferença: a perspectiva dos estudos Culturais. $15^{\mathrm{a}}$ ed. RJ, Petrópolis: Vozes, 2014.

SKLIAR, Carlos. Pedagogia (improvável) da diferença: e se o outro não estivesse aí? RJ: DP\&A, 2003.

SOUTHWELL, Myriam. Em torno da construção de hegemonia educativa: contribuições do pensamento de Ernesto Laclau ao problema da transmissão da cultura. In: MENDONÇA, Daniel de; RODRIGUES, Léo Peixoto. Pós-estruturalismo e teoria do discurso: em torno de Ernesto Laclau. $2^{\text {a }}$ ed. Porto Alegre: EDIPUCRS, 2014.

SOUZA, Marina de Mello e. África e Brasil africano. São Paulo: Ática, 2006.

TAYLOR, Charles (et al). Multiculturalismo: examinando a política de reconhecimento. Lisboa: Instituto Piaget, 1994.

VELASCO, Diego Bruno; BARCELLOS, Vitor Andrade. Demandas do tempo presente e sentidos de cidadania: redefinições e deslocamentos no currículo de História (anos 1980 x anos 2010). In: MONTEIRO, Ana Maria; GABRIEL, Carmen Teresa; ARAÚJO, Cínthia Monteiro de; COSTA, Warley (Org.). Pesquisa em ensino de história: entre desafios epistemológicos e apostas políticas. RJ: Mauad X/ Faperj, 2014.

WOODWARD, Kathryn. Identidade e diferença: uma introdução teórica e conceitual. In: SILVA, Tomaz Tadeu (Org.). Identidade e diferença: a perspectiva dos estudos Culturais. $15^{\mathrm{a}}$ ed. Petrópolis, RJ: Vozes, 2014.

YABETA, Daniela. A escola quilombola da Caveira e outros casos: notas de pesquisa sobre educação e comunidades negras rurais no Rio de Janeiro (2013-2015). In: MATTOS, Hebe (Org.). História oral e comunidade: reparações e culturas negras. São Paulo: Letra e Voz, 2016.

ZIZËK, Slavoj. Multiculturalismo o La lógica cultural del capitalismo multinacional. In: JAMESON, Friedric; ZIZËK, Slavoj. Estudios Culturales: reflexiones sobre el multiculturalismo. Buenos Aires: Paidós, 1998. 